\title{
Example Sentences in Bilingual Specialised Dictionaries Assisting Communication in a Foreign Language
}

Sandro Nielsen, Centre for Lexicography, Aarhus University, Denmark and International Centre for Lexicography, University of Valladolid, Spain (sn@bcom.au.dk)

\begin{abstract}
Practitioners, researchers and translators are persons who often have to communicate about domain-specific issues in a foreign language and may consult bilingual specialised dictionaries for help. However, many specialised dictionaries focus on terms even though studies of the foreign language text production process reveal that this also includes grammar, language conventions, genre conventions and style. Specialists can be expected to know conventions and style in their own source language culture but cannot be expected to know how these are realised in a foreign language. Bilingual specialised dictionaries can help users if they contain domain-specific example sentences illustrating how source language convention and style can be transposed to a foreign language. This means that bilingual specialised dictionaries should not merely help users translate terms but be lexicographical tools designed to assist in foreign language communication so that they provide help to practitioners, researchers and translators who produce specialised texts in a foreign language using proper conventions and style.
\end{abstract}

Keywords: SPECIALISED LEXICOGRAPHY, ONLINE DICTIONARIES, PRINTED DICTIONARIES, TECHNICAL DICTIONARIES, SPECIALISED COMMUNICATION, EXAMPLES, LEXICOGRAPHICAL FUNCTIONS, TEXT PRODUCTION, USER NEEDS, WRITING, TRANSLATION

Opsomming: Voorbeeldsinne in tweetalige vakwoordeboeke help met kommunikasie in 'n vreemde taal. Praktisyns, navorsers en vertalers moet dikwels in 'n vreemde taal oor vakspesifieke sake kommunikeer en raadpleeg daarvoor dan dalk tweetalige vakwoordeboeke. Baie vakwoordeboeke se fokus is op terme alhoewel navorsing oor teksproduksie in 'n vreemde taal daarop wys dat grammatika, taalkonvensies, genrekonvensies en styl ook ter sake is. Van vakspesialiste kan dit verwag word om vertroud te wees met taalkonvensies en styl in hulle eie brontaal, maar nie met die weergawe daarvan in 'n vreemde taal nie. Tweetalige vakwoordeboeke kan gebruikers help deur vakspesifieke voorbeeldsinne in te sluit wat wys hoe brontaalkonvensies en styl na die doeltaal oorgedra moet word. Dit beteken dat tweetalige vakwoordeboeke nie net gebruikers moet help om terme te vertaal nie maar hulle moet leksikografiese instrumente wees wat ontwerp is om met vreemdetaalproduksie te help. Daardeur ondersteun hulle praktisyns, navorsers en vertalers wat vaktekste in 'n vreemde taal moet skep om die regte konvensies en styl te benut. 
Sleutelwoorde: AANLYN WOORDEBOEKE, GEBRUIKERSBEHOEFTES, GEDRUKTE WOORDEBOEKE, GESPESIALISEERDE KOMMUNIKASIE, LEKSIKOGRAFIESE FUNKSIES, SKRYF, TEGNIESE WOORDEBOEKE, TEKSPRODUKSIE, VAKLEKSIKOGRAFIE, VERTALING, VOORBEELDE

\section{Introduction}

As a result of increasing activities across borders and cultures, more and more people need to communicate in a foreign language in a range of situations related to specific subject fields. Translators often help businesses and specialists communicate in foreign languages. Practitioners from various domains have become more internationally oriented because they work for multinational organisations, have been posted or seconded abroad. Researchers from all types of disciplines study not only their local environments but also look for inspiration in foreign environments to a greater extent than ever before and therefore must be able to understand foreign language source material. In addition, practitioners as well as researchers are expected to act in international settings by publishing articles in journals, by presenting papers at conferences, and by participating in negotiations or discussions. It is imperative that translators and domain specialists communicate correctly in a foreign language about the subject matter concerned and in this light, it is relevant to examine whether, and if so how, dictionaries can provide help in communicative situations.

Specialised dictionaries can contain a great variety of data types that help practitioners, researchers and translators successfully meet challenges in foreign language communication. Equivalents are the obvious type of data, and so are examples of language use. Example sentences represent one type of example that have been discussed in the lexicographical literature, but the study of example sentences in specialised dictionaries designed to provide help in communicative situations in a foreign language has so far been relatively limited. This paper discusses how example sentences in bilingual specialised dictionaries can facilitate domain-specific communication in a foreign language. The following discussion first delimits the scope of examples in lexicographical products and defines the concept of specialised dictionaries, then looks at the relationship between dictionaries and the production of written texts in a foreign language, and finally discusses how lexicographers may use example sentences to assist translators, researchers and practitioners in their foreign language communication.

\section{Defining examples and specialised dictionaries}

One type of lexicographical data that lexicographers can include in their dictionaries with a view to helping practitioners, researchers and translators com- 
municate in a foreign language is often referred to as examples. A study of the existing literature reveals that the general term example is used in more than one sense. For instance, Svensén (2009: 281) explains that the term "comprises all types of indications consisting of word combinations (phrases, clauses, sentences) that contain a form of the lemma sign, irrespective of whether they are provided with an indication of meaning or not." This description applies, in particular, to monolingual dictionaries, such as dictionaries intended for text production by foreign language users, though bilingual dictionaries with the same function may also contain lexicographical examples. In order to narrow down the discussion that follows, focus will be on sentences, mainly because they may illustrate the use of equivalents in context as well as the translation of lemmas (or headwords) in context relevant for specialised communication in a foreign language. Another reason is that collocations and phrases may exemplify the use of lemmas in monolingual dictionaries, but in bilingual dictionaries "the majority of sub-entries provide one-to-one translation equivalents. They exemplify nothing" (Jacobsen et al. 1991: 2783). Finally, a recent study shows that "The data support the conclusion that phrases are less useful at providing support than sentences" (Hiles 2011: 304).

Lexicographers often divide examples into different types. Zöfgen (1986) proposes a classification based on the properties or characteristics of lemmas in monolingual dictionaries for learners such as, examples showing grammar data, collocations, clauses and phrases. Harras (1989) distinguishes between syntactic data, collocations and sentences illustrating usage in monolingual dictionaries, among others. Furthermore, Bergenholtz (1995: 137-142) discusses examples in specialised dictionaries and distinguishes between collocations, grammatical examples, citations, citation examples and competence examples; overall, he favours the use of example sentences.

One reason for the different understandings of and approaches to examples in dictionaries appears to be the influence of linguistics and lexicology. Jacobsen et al. (1991: 2784), who address examples in bilingual general dictionaries, suggest that examples should not be examined using a functional approach (understood as linguistic functions) but from a formal perspective (understood as components in dictionaries); in their words, an example in a dictionary cannot "be functionally defined in terms of the type of information it provides; it follows from this that it is not (meta)linguistically defined in terms of the linguistic categories (syntax, semantics, morphology) involved" (Jacobsen et al. 1991: 2784). After this brief discussion of examples in lexicography, it is appropriate to provide a working definition of lexicographical example sentences intended to assist translators and specialists communicate in a foreign language:

Example sentences are full sentences that provide data concerning the source language lemma, the target language equivalent or a combination of both enabling specific types of users to communicate successfully in a foreign language in domain-specific situations. 
A specialised dictionary, whether printed or online, is a complex unit. Firstly, the dictionary has several surface features, i.e. the printed or online dictionary contains a number of distinct components that constitute the dictionary when users consult it. For example, printed dictionaries contain wordlists as well as other supporting components such as appendices and user guides, while online dictionaries contain components such as search sites, results sites, and various supporting components. Secondly, the dictionary has three underlying features, namely:

(1) it has been designed to fulfil one or more functions, i.e. provide a specific type of help in specific types of situation to specific types of user;

(2) it contains data that have been selected because they help to fulfil its function(s);

(3) it has structures that organise its data into the task of fulfilling its function(s).

Specialised dictionaries can be designed to help users in a range of situations, of which two are the most general types. According to Nielsen (2012: 114), dictionaries with communicative functions provide help in ongoing or planned communicative situations, while dictionaries with cognitive functions provide help to those who want to acquire knowledge about factual or linguistic matters. Specialised dictionaries can therefore be designed to:

- provide help to translate specialised texts

- provide help to produce specialised texts

- provide help to understand specialised texts

- provide help to acquire general or specific knowledge about factual or linguistic matters from one or more subject fields

This means that specialised dictionaries are lexicographical tools that function as utility products which, through their surface and underlying features, provide specific types of help to specific types of user in specific types of usage situation related to one or more domains and the related domain-specific language. In order to make such information tools, it is relevant to study the extralexicographical situation when translators, researchers and practitioners produce written texts in a foreign language.

\section{Dictionaries and text production in a foreign language}

People who need to communicate about domain-specific matters in a foreign language will need dictionaries that can help them solve specific problems. At a very general level this may be summed up as follows: the data contained in the dictionaries (e.g. in example sentences) should enable practitioners, researchers 
and translators to write grammatically and idiomatically correct utterances without compromising their factual contents. Bergenholtz and Nielsen (2002: 14) suggest that the general purpose of dictionaries intended for text production is to help users become aware of the elements of good writing within a subject field; this includes aspects such as grammatical, syntactic, stylistic and terminological questions that arise during the writing process. These aspects are important when translating source texts into a foreign language as well as when writing texts directly in the foreign language since the only major step in text production that distinguishes the two types of situation is the analysis of source language texts to be translated. When identifying the steps in producing texts, lexicographers should use a method that is workable in lexicography.

A broad outline of the writing process may be used to determine the choices that lexicographers have to make. Marsen (2003: 2-13) explains that the process of writing texts has three stages: a planning, an execution and a finalisation stage. In most cases, writing manuals provide help in the planning stage so lexicographers should focus on the execution and the proofreading stages. Rude (2002: 15-16) shows that the execution stage involves the writing of a draft text, followed by the revising and editing of the text, and that proofreading extends revising and editing into the finalisation stage. Similarly, Byrne (2006: 17) discusses technical translation and breaks down the translation process into five tasks: interpretation of the source text, writing of the translation, research needed for the first two tasks, checking the draft translation for errors, and making any necessary corrections and adjustments. Specialised dictionaries for text production can thus be described as tools that provide help to draft, revise and edit specialised texts.

Text production occurs at two general levels. The macro-level concerns paragraphs and larger units of text, whereas the micro-level concerns words, collocations, phrases, sentences, and textual conventions. The micro-level is particularly relevant to specialised dictionaries because specialists and translators need help at this level when writing texts in a foreign language. Mossop (2007: 27-33) explains that when they revise and edit, writers make sure that their texts follow generally accepted grammar and spelling rules, that they have used the correct terminology, and that the finished texts are unambiguous. Finally, writers and copyeditors look for errors and correct them as appropriate. The process of specialised translation involve similar aspects: "Technical translation involves detailed knowledge of the source and target cultures, target language conventions, text type and genre conventions, register, style, detailed understanding of the audiences" (Byrne 2006: 7). It follows that specialists and translators producing texts in a foreign language are challenged at the microlevel and lexicographers should therefore focus on this level when making dictionaries designed to provide help to write and translate specialised texts.

When selecting data types, lexicographers should take into consideration the competences of users. By studying the foreign language text production process and by identifying the relevant skills and competences of practitioners, 
researchers and translators, lexicographers have a good basis for selecting data that can best satisfy user needs. Several methods for profiling intended dictionary users exist but few focus on specialised dictionaries. Bergenholtz and Nielsen (2006: 286) propose a list of questions that relate to categories of skills and knowledge possessed and for the discussion below, the following overall competences are assumed:

- Practitioners, researchers and translators master their native language at a high level

- Practitioners and researchers master the foreign language at a low or medium level

- Translators master the foreign language at a high level

- The experience of practitioners and researchers in producing domain-specific texts in the foreign language is at a low level

- The experience of translators in producing domain-specific texts in the foreign language is at a medium or high level

- The general cultural and factual knowledge of practitioners, researchers and translators is at a high level

- Practitioners and researchers master their subject field in their native culture at a high level

- Translators master a subject field in their native culture at a medium level

- Practitioners, researchers and translators master their culture-dependent subject field in the foreign culture at a low level (or not at all)

- Practitioners, researchers and translators master their culture-independent subject field in the foreign culture at a medium or high level

- Practitioners and researchers master the native language of their subject field at a high level

- Practitioners and researchers master the language of their subject field in the foreign culture at a low or medium level

- Translators master the two languages of the native and foreign subject fields at a medium or high level

A list like the above enables lexicographers to respond to the general needs of translators, researchers and practitioners who have to communicate in a foreign language. It would appear from the above list that, in communicative situations, some will think in their native language and translate into the foreign language, others will think in their native language and translate into the foreign language as well as think in the foreign language and write directly in the foreign language, and yet others will think in the foreign language and 
write directly in the foreign language. Lexicographers should take these factors into consideration when deciding on the type and form of example sentences that are intended to help users communicate about their subject field in a foreign language.

\section{Example sentences supporting text production}

When communicating in a foreign language, three general topics come into play: terms, language structures, and genre conventions. These topics are particularly important when the native language of translators and specialists allows the use of terms, language structures and genre conventions that differ from the functionally equivalent terms, structures and conventions in the foreign language. Furthermore, as example sentences are dictionary components, lexicographers should be able to use such sentences to show or translate all three as they are found at the micro-level of text production. This is in line with the comment made by Jacobsen et al. (1991: 2787) in respect of general dictionaries, "Examples, if judiciously selected, can demonstrate collocational, stylistic, syntactic, morphological, and cultural features of words and phrases." If this statement is compared to the description by Byrne (2006) quoted above (that technical translation requires knowledge of the two cultures involved, targetlanguage conventions, genre conventions, register, and style), lexicographers should consider using example sentences to show how specialised communication can be performed in a foreign language.

Style, i.e. the characteristic and correct way of speaking and writing in a specific domain, may be regarded as an overarching feature of specialised text production. One of the misconceptions about technical and other specialised texts is that style does not matter, since the factual content overshadows everything else; however, according to Byrne (2006), this misconception is completely unfounded:

Perhaps the problem stems from differing opinions of the nature of style and the popular belief that it relates exclusively to literature. If we look at style from a literary point of view, then it does not have any place in technical translation. But if we regard style as the way we write things, the words we choose and the way we construct sentences, the style is equally, if not more, important in technical translation than in other areas because it is there for a reason, not simply for artistic or entertainment reasons. (Byrne 2006: 4)

As a result, lexicographers should allow room for style in dictionaries intended to help specialists and translators produce domain-specific texts in a foreign language. Example sentences may represent or exemplify the grammatical properties where irregularities are concerned, as experts, researchers and translators can only be expected to know regular grammatical rules of the foreign language. One example sentence will usually suffice but in some cases, lexicographers should consider whether two or more sentences would be appro- 
priate. Consider the following two sentences exemplifying the use of the British legal term counsel (i.e. lawyer):

- The judge asked counsel for the defence to explain. (Longman Dictionary of Contemporary English)

- The plaintiff appeared in court with his solicitor and two counsel. (English Law Dictionary)

The first example sentence demonstrates that counsel is used correctly without an article when it refers to a lawyer, even when followed by a post-modifying prepositional phrase. The second example sentence shows that counsel inflects irregularly for the plural, as no inflectional affix is added to the stem. It would be difficult to find (or construct) a typical or natural sentence showing both grammatical irregularities and at the same time be easy to understand. However, the danger of including too much data in example sentences is that users may overlook or misinterpret the data because they do not know what to look for.

Lexicographers can also use example sentences to show incorrect use of terms. A Dictionary of Modern Legal Usage, intended to help lawyers produce better legal writings, often provides examples of incorrect use to make lawyers aware that specific terms are often used wrongly in practice. The article treating the term counsel contains the following authentic example sentence with the lexicographers comment in square brackets:

- [F]our lawyers were named Nov. 25 to serve as counsels [read counsel] for the transition. (A Dictionary of Modern Legal Usage)

Even though they are from monolingual dictionaries, the above three example sentences exemplify the use of specialised language. Such illustrations are useful to both native and non-native speakers of English; the main reason is that the specialised language of domains use words, structures and conventions that differ from those in everyday language and that specialist style allows the use of structures and conventions that are seldom, if ever, used in general language. In bilingual dictionaries, the three English example sentences above will illustrate the use of the equivalent (in this case counsel) and thus be addressed to the equivalent, whereas the sentences would be addressed to the lemma in monolingual dictionaries.

An issue that has been discussed in the literature is whether example sentences in bilingual dictionaries should be in the source language (SL) as well as in the target language (TL). Adamska-Sałaciak (2006: 493-494) "believe[s] that there is no need to translate examples" but modifies this by saying that "As far as systematic translation of all examples is concerned, I can see some justification for the practice in dictionaries targeted at beginners." These comments concern general dictionaries, but if domain-specific communication contains terms, structures and conventions that are seldom used in general language, lexicographers may have additional justification for translating example sen- 
tences in specialised dictionaries. The existing literature also contains different opinions and positions as to the translation of examples in general dictionaries, for instance:

In bilingual lexicography it is not sufficient to refer to the "SL example" or the "TL example" for a given lemma. The SL and TL halves of the example are closely linked functionally, and must be considered to be a unit formally. If the primary focus of the bilingual dictionary is translation, then the primary function of the bilingual dictionary example is to exemplify translation. A definition of the form of an example must logically include its SL and TL halves. (Toope 1996: 18)

An example may clarify the position. The following English sentence may be a target-language example sentence in an imaginary German-English technical dictionary:

- Figure 1 contains the characteristics of diodes of equal power rating. (Hann 1992: 190)

This sentence illustrates the use of an equivalent in context, but tells users nothing about the relationship between this sentence and any source language utterance. Only implicitly does the English sentence show how a German utterance with a similar factual message (provided users can come up with one) may be translated - the SL half of the example sentence is missing. Nevertheless, the sentence does show one instance of target-language usage. If it contains example sentences in SL as well as their translations in TL, the GermanEnglish technical dictionary may provide the following example sentence:

- In Abbildung 1 ist das Kennlinienfeld leistungsgleicher Dioden angegeben.

- Figure 1 contains the characteristics of diodes of equal power rating. (Hann 1992: 190)

Now the two halves of the example sentence are present and it becomes clear that the sentence shows stylistic differences in technical discourse between the two languages, in that the German sentence begins with a prepositional phrase and is phrased in the passive voice. In contrast, the English translation shows that target language style conventions prefer the use of an active construction with no prepositional phrase. This difference is made explicit only when the SL half and the TL half of the example sentence are presented. Similarly, an imaginary Danish-English technical dictionary may contain the following example sentence:

- En indstillelig momentkobling slår spindlen fra før tapbrud.

- Adjustable torque control stops spindle to prevent tap breakage. (Thürmer 1986: 135) 
This example shows an English equivalent in context and explicitly illustrates a stylistic difference between the two languages. The Danish half contains an indefinite article ("En indstillelig") and a definite article ("spindlen"). In contrast, the English half shows that English conventions prefer the non-use of articles when correctly expressing the meaning of the Danish utterance. The example sentence also shows another difference: Danish apply general-language conventions allowing the use of articles, whereas English apply speciallanguage conventions that do not include articles in this particular context. Based on their assumed skills and competences, translators, researchers and practitioners are unlikely to be aware of such differences, something which justifies the inclusion of bilingual example sentences.

There is no doubt that lexicographers can use example sentences to illustrate style conventions in a foreign language, but users may not immediately notice that example sentences show such conventions. So the challenge is for lexicographers to present style conventions in a way so that users will not have to guess that example sentences provide data that help to produce foreign language utterances complying with domain-specific style conventions. If the above imaginary bilingual dictionaries are printed lexicographical tools, lexicographers may place the example sentences in specific boxes with informative headlines; see Example 1.

\section{Style convention: passive and active sentences}

In Abbildung 1 ist das Kennlinienfeld leistungsgleicher Dioden angegeben.

Figure 1 contains the characteristics of diodes of equal power rating.

Example 1: Example sentence with informative headline in German-English technical dictionary

The imaginary dictionary may also be an online lexicographical tool and lexicographers may present the example sentence in the same way as illustrated in Example 1. However, lexicographers can use other features to explicitly inform users of the illustrative function; for instance, the example sentence may be placed in a box with an icon, as shown in Example 2.

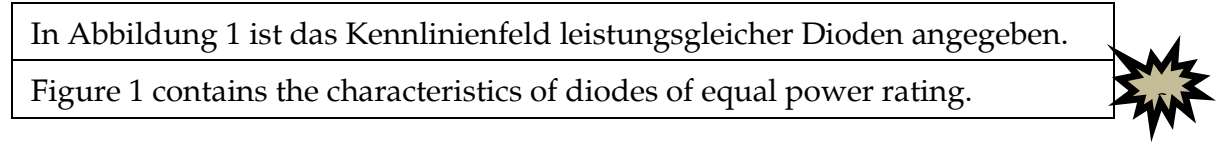

Example 2: Example sentence accompanied by icon and possible hover box

Icons may be combined with hover boxes, also called mouse-overs or mouse hovers, so that users place the pointer over the icon and a box containing, e.g. 
the text "Style conventions: passive and active sentences", appears without the need to click.

Lexicographers may also present example sentences in printed and online dictionaries using boldface, italics and different colours for specific style conventions in the SL and/or TL half. The use of colours should be accompanied by colour legends, e.g. red = grammar; yellow = culture; blue = textual convention. Alternatively, lexicographers can show the meaning of colours through hover boxes so that users place the pointer over a coloured text part and a box automatically appears with an informative text. In online dictionaries, lexicographers may further consider to let users press the coloured text parts on a touchscreen instead of using pointers to make informative hover boxes appear.

A related but slightly different approach lexicographers can use in both printed and online dictionaries is to present entire SL sentences but only partial translations, as illustrated in Example 3.

appropriate adj. 1. geeignet, entsprechend, sinnvoll, passend: [.....] To assist in selecting the most appropriate procedure, let us consider the advantages and disadvantages of each alternative (passendste Vorgehensweise). [.....] It is appropriate to specify that the control system be able to handle 1000 analog inputs and outputs (es ist zweckmäßig/sinnvoll vorzuschreiben, dass ...).

Example 3: Partially translated example sentences from Phraseological Dictionary English-German

Example 3 shows how text parts of SL sentences can be highlighted in boldface and how these passages can be translated and presented in italics. The first example sentence illustrates the different ways to compare adjectives in English and German, while the second sentence shows that an English lemma has two possible translations in German, of which one is given as an alternative to the equivalents presented in the head of the article. The advantage of highlighting passages in SL and TL halves is that lexicographers draw attention to the stylistic, linguistic or genre-related points they want to convey to users (Prinsloo and Gouws 2000: 148), but a disadvantage is that users may be distracted by the linguistic and factual complexity of relatively long sentences.

Writers of specialised texts know that the use of textual or genre conventions vary considerably. Mayoral Asensio (2007: 52) describes a genre as a class of texts perceived as such by readers of the texts who recognise conventions regarding textual structure and other linguistic elements used in similar communicative situations. As indicated in Section 3 above, lexicographers should consider those conventions that appear at the micro-level since they are likely to differ from one genre and domain to another and since different cultures and languages have their own ways in which to realise the conventions. Practitio- 
ners, researchers and translators therefore need dictionaries that help them produce texts that conform to the conventions in the target language, because "Failing to comply with target language text conventions can undermine the credibility of the text, the author and the information in the text" (Byrne 2006: 4).

Specialists and translators are generally expected to be familiar with genre-specific conventions in their own language within one or few subject fields but only few genre conventions in a foreign language. Nielsen (2000) discusses genre conventions used in statutes and suggests that since culture dictates convention, good bilingual translation dictionaries should help users select the proper foreign language conventions. Law is a culture-dependent subject field in that the legal structure and the legal language in one culture differs from the structure and language in another culture; hence law is one of the fields in which those who communicate in a foreign language need help. Example 4 contains the same sentence in seven languages and is from a judgment passed by the Court of Justice of the European Union; it shows the use of textual conventions when referring to European Union directives.

\begin{tabular}{|l|l|}
\hline Danish & Direktivets artikel 14, stk. 1, litra c), har følgende ordlyd: \\
\hline English & Article 14(1)(c) of that directive is worded as follows: \\
\hline French & L'article 14, paragraphe 1, sous c), de ladite directive est libellé comme suit: \\
\hline German & Art. 14 Abs. 1 Buchst. c der Richtlinie 2006/54 bestimmt: \\
\hline Spanish & $\begin{array}{l}\text { El artículo 14, apartado 1, letra c), de esa Directiva tiene la siguiente redac- } \\
\text { ción: }\end{array}$ \\
\hline Swedish & Enligt artikel 14.1 c i samma direktiv gäller följande: \\
\hline Dutch & Artikel 14, lid 1, sub c, van die richtlijn is als volgt geformuleerd: \\
\hline
\end{tabular}

Example 4: The use of textual conventions in different languages in a regulatory genre

The textual conventions in Example 4 have been highlighted using boldface and the sentences show that languages realise the conventions in different ways. The English and the Swedish conventions differ most from those of the other languages in that they are the shortest passages with only one word (term). The other languages use combinations of words and abbreviations with or without brackets, commas and full stops. Practitioners, researchers and translators cannot generally be expected to know such specific textual conventions in a foreign language. Accordingly, lexicographers should consider including example sentences in their dictionaries that help users write foreign language textual conventions when usage in the source language and the target language differs. An imaginary French-English dictionary of law may contain the example sentence shown in Example 5. 
L'article 14, paragraphe 1 , sous c), de ladite directive est libellé comme suit:

Article 14(1)(c) of that directive is worded as follows:

Example 5: Example sentence providing help to translate French textual conventions into English

Example 5 illustrates that example sentences can help specialists and translators select the correct way in which to realise conventions in a foreign language. By highlighting the relevant passages containing the conventions, lexicographers draw the attention of users to the genre-related points they want to convey and users receive explicit help with explicit points.

The lexicographical structure that determines the interplay between data in dictionaries is the distribution structure. If lexicographers decide to place the data on grammar, textual conventions and style inside articles, users will find the data in close proximity to the lemmas. Consequently, users will have direct access to these types of data through the wordlist in printed dictionaries and some online dictionaries or through the search for lemmas or words in examples in online dictionaries. However, the data types have to be included in articles in addition to other data types (e.g. morphological data, definitional data, equivalents, collocations, synonyms and cross-references) leading to possible data overload. Furthermore, lexicographers will have to include identical or near-identical grammar, genre-related and style data in a large number of articles and this may increase the length of articles, which takes up space in printed dictionaries. Spatial constraints are not a problem in online dictionaries, but if articles or other search results take up more space than can be shown on a screen, users may overlook important data.

When lexicographers have placed functionally relevant data in the dictionary or database, the next question is how users will be able to find the data. In printed dictionaries, example sentences will be scattered all over the book and in order to help practitioners, researchers and translators find them lexicographers may include one or more indexes in the front or back matter. This solution is used in A Dictionary of Modern Legal Usage, which has a "Classified Guide to Essay Entries" in its front matter divided into 5 sections: style; grammar and usage; legal lexicology and special conventions; word formation, inflection, spelling and pronunciation; punctuation and typography. Each section contains a list of lemmas so that users who look for data on, for instance, style, can see in which articles they can find style data related to the lemmas. If it contains example sentences dealing with grammar, textual conventions and style, a bilingual specialised dictionary may contain an index divided in three sections, or three indexes, listing the articles that include example sentences on grammar, textual conventions and style, respectively.

Lexicographers may opt for similar solutions in online dictionaries, i.e. presenting one or more indexes listing the lemmas to which example sentences are addressed. Users can then click on lemmas and be brought directly to full 
articles containing the relevant example sentences. Online technology allows lexicographers to adopt other solutions where, for instance, users click lemmas in indexes and are only presented with e.g. lemmas, definitions and example sentences, i.e. not full articles in the traditional sense, but merely those data types addressed to lemmas that are relevant for understanding example sentences. This option will often allow practitioners, researchers and translators to find example sentences on the screen without having to scroll. This means that, in online dictionaries, it does not matter where in the database example sentences are placed; the important point is for lexicographers to select a data presentation structure that presents example sentences dealing with grammar, textual conventions and style so that they are easy to find. Moreover, online dictionaries may also allow users to search for words and terms directly in all example sentences in the database and then present those sentences (in both SL and TL) that contain the words and terms searched for.

\section{Concluding remarks}

This paper has discussed how example sentences in specialised dictionaries can facilitate text production in and translation into a foreign language. When practitioners, researchers and translators communicate about domain-specific matters in a foreign language they need help with terms as well as other textual elements at the micro-level of text production. By studying the text production process, lexicographers can identify where the challenges are, and it appears that in addition to terms specialists and translators need help with e.g. cultural differences, language conventions, genre conventions and style. One way in which dictionaries can provide help with these elements of foreign language text production is when lexicographers include example sentences in the source language and their translation in the target language that illustrate and exemplify how practitioners, researchers and translators can communicate properly, i.e. grammatically, idiomatically and stylistically correct. To some extent, lexicographers can adopt the same or similar solutions in both printed and online specialised dictionaries, but online technology offers additional ways in which to give easy access to example sentences. This means that lexicographers should not regard bilingual specialised dictionaries as lists of terms and their translation but as lexicographical information tools that provide help to practitioners, researchers and translators who produce specialised texts in a foreign language with grammar, textual conventions and style.

\section{References}

\section{Dictionaries}

A Dictionary of Modern Legal Usage = Garner, B.A. 1995. A Dictionary of Modern Legal Usage. Second edition. New York/Oxford: Oxford University Press. 
Dictionary of Law = Collin, P.H. 1993. English Law Dictionary. Teddington: Peter Collin Publishing. Longman Dictionary of Contemporary English = Summers, D. (Ed.). 2003. Longman Dictionary of Contemporary English. Fourth edition. Harlow: Longman.

Phraseological Dictionary English-German = Kraus, R. and P. Baumgartner. 2011. Phraseological Dictionary English-German. General Vocabulary in Technical and Scientific Texts. Berlin/ Heidelberg: Springer.

\section{Other literature}

Adamska-Sałaciak, A. 2006. Translation of Dictionary Examples - Notoriously Unreliable? Corino, E. et al. (Eds.). 2006. Atti del XII Congresso Internazionale di Lessicografia, Torino, Italia, September 6th-9th 2006: 493-501. Alexandria: Edizioni dell'Orso.

Bergenholtz, H. 1995. Linguistic Information. Bergenholtz, H. and S. Tarp (Eds.). 1995. Manual of Specialised Lexicography. The Preparation of Specialized Dictionaries: 111-142. Amsterdam/Philadelphia: John Benjamins.

Bergenholtz, H. and S. Nielsen. 2002. Terms in the Language of Culture-dependent LSP Dictionaries. Lexicographica. International Annual for Lexicography 18: 5-18.

Byrne, J. 2006. Technical Translation: Usability Strategies for Translating Technical Documentation. Dordrecht: Springer.

Court of Justice of the European Union. 2014. Case C - 167/12, C.D. v S.T. [online]. Available at: http:// eur-lex.europa.eu/legal-content/EN/TXT/?uri=CELEX\%3A62012CJ0167\&qid=1399112550800 [Accessed 15 April 2014].

Hann, M. 1992. The Key to Technical Translation. Volume 2: Terminology/Lexicography. Amsterdam/ Philadelphia: John Benjamins.

Harras, G. 1989. Zu einer Theorie des lexikographischen Beispiels. Hausmann, F.J. et al. (Eds.). 1989. Dictionaries. An International Encyclopedia of Lexicography. Vol. 1: 607-614. Berlin: Walter de Gruyter.

Hiles, L. 2011. Categorising Example Sentences in Dictionaries for Research Purposes. Lexikos 21: 298-304.

Jacobsen, J., J. Manley and V.H. Pedersen. 1991. Examples in the Bilingual Dictionary. Hausmann, F.J. et al. (Eds.). 1991. Dictionaries. An International Encyclopedia of Lexicography. Vol. 3: 27822789. Berlin: Walter de Gruyter.

Marsen, S. 2003. Professional Writing. The Complete Guide for Business, Industry and IT. Basingstoke: Palgrave Macmillan.

Mayoral Asensio, R. 2007. Specialised Translation. A Concept in Need of Revision. Babel 53(1): 48-55.

Mossop, B. 2007. Revising and Editing for Translators. Manchester/Kinderhook: St. Jerome Publishing.

Nielsen, S. 2000. Translation Strategies for Culture-Specific Textual Conventions in Bilingual Dictionaries. Lexicographica. International Annual for Lexicography 16: 152-168.

Nielsen, S. 2012. Online Law Dictionaries: How to Provide Help for EFL Text Production by Law Students. Fachsprache/International Journal of Specialized Communication 23(3-4): 112-124.

Prinsloo, D.J. and R.H. Gouws. 2000. The Use of Examples in Polyfunctional Dictionaries. Lexikos 10: $138-156$.

Rude, C.D. 2002. Technical Editing. New York: Longman. 
Svensén, B. 2009. A Handbook of Lexicography. The Theory and Practice of Dictionary-making. Cambridge: Cambridge University Press.

Thürmer. 1986. Dansk gevindskæreværktøj siden 1898. Danish Thread Cutting Tools since 1898. Frederiksberg: Thürmer \& Co.

Toope, M. 1996. Examples in the Bilingual Dictionary. Unpublished M.A. Thesis, University of Ottawa, School of Translation and Interpretation, Ottowa. [Online]. Available at: http://www. ruor.uottawa.ca/en/bitstream/handle/10393/9942/MM15769.PDF?sequence=1 [Accessed 15 April 2014].

Zöfgen, E. 1986. Kollokation - Kontextualisierung - (Beleg-)satz. Anmerkungen zur Theorie und Praxis des lexikographischen Beispiels. Barrera-Vidal, A. et al. (Eds.). 1986. Französische Sprachlehre und bon usage. Festschrift für Hans Wilhelm Klein zum 75. Geburststag: 219-238. München: Max Hueber. 